\title{
Surgical Strategies for the Management of Perihilar Cholangiocarcinoma
}

\author{
Mohamed Abdel Wahab, Ahmed Shehta, Mahmoud Ali
}

\section{Corresponding author:}

Mohamed Abdel Wahab, MD

Professor of Hepato-biliary Surgery

Chair of Liver Transplantation Unit

Liver Transplantation Unit

Gastrointestinal Surgery Center

College of Medicine

Mansoura University, Egypt

Gastrointestinal Surgery Center

Gehan Street, Mansoura, Egypt

Postal code: 35516

Mobile: +2 01223134160

E-mail:Wahab_m_eg@yahoo.com
Gastrointestinal Surgery Center, Department of Surgery, College of Medicine Mansoura University, Mansoura, Egypt

\section{ABSTRACT}

Cholangiocarcinoma is a fatal cancer arising from the biliary endothelium. Perihilar cholangiocarcinoma ( $\mathrm{pCCA}$ ) is the most common variant of cholangiocarcinoma, with increasing incidence worldwide. Most pCCA patients present with unresectable disease at the time of diagnosis, and many patients are found to be unresectable after surgical exploration. pCCA carries a poor prognosis as more than $65 \%$ of the patients are presented with non-resectable disease at the time of diagnosis, and about $10 \%$ to $45 \%$ of patients are found to be unresectable after surgical exploration. Surgical resection is the main stay of treatment of pCCA. The close anatomic relationship of pCCA to major hepatic vascular structures with subsequent frequent vascular invasion makes surgical resection one of the most challenging surgical procedures. To achieve a radical resection for pCCA, resection should involve resection of involved intraand extrahepatic biliary tree with safety margin, resection of related hemi-liver according to the tumor extension, caudate lobectomy, lymphadenectomy including loco-regional lymph nodes and biliary tract reconstruction through biliary-enteric anastomoses. Despite the modern major advancements in surgical techniques and multidisciplinary management over the past years, surgical resection remains associated with high perioperative morbidities and poor survival outcomes. This aim of this review is to address the recent advances in surgical treatment for pCCA and its impact on patients' survival.

Key words: perihilar cholangiocarcinoma, surgical resection, liver transplantation

\section{INTRODUCTION}

Cholangiocarcinoma (CCA) is the most common biliary tract malignancy and the second most common primary hepatic malignancy accounting for about 10-20\% of primary liver cancers (1). According to its site of origin and the tumor biology, CCA is divided into three subtypes, intrahepatic, perihilar and, distal CCA. Perihilar cholangiocarcinoma (pCCA) is the most common form worldwide accounting for about $50-67 \%$ of all cases (2). pCCA was firstly described by Gerald Klatskin in 1965 (3).

Nowadays, surgical resection is the main stay of treatment of pCCA. Radical resection of PCCA is one of the most challenging surgical procedures due to 
the close anatomic relationship of pCCA to major hepatic vascular structures with subsequent vascular invasion (4). However, pCCA carries a poor prognosis as more than $65 \%$ of the patients are presented with nonresectable disease at the time of diagnosis, and about $10 \%$ to $45 \%$ of patients are found to be unresectable after surgical exploration (5-7). Also, surgical resection is associated with substantial perioperative morbidity (4).

The aim of this review is to provide an overview of pCCA and address recent surgical challenges and strategies in the management of pCCA.

\section{ETIOLOGY}

The etiology of pCCA is not clearly understood. Several risk factors have been associated to the development of pCCA including primary sclerosing cholangitis (8), liver fluke infestation in South-East Asia (9), Choledochal cysts and Caroli's disease (10), hepatolithiasis, and exposure to toxic agents such as thorotrast and dioxin (11).

\section{STAGING}

Several staging systems had been proposed for pCCA. Bismuth and Corlette firstly proposed a classification system for pCCA depending on the anatomical extension of the disease (table 1)(12). The Memorial Sloan-Kettering Cancer System (MSKCC) proposed another classification system for pCCA depending the tumor extent to the second order biliary radicals, portal venous invasion, and hepatic lobar atrophy (table 2)(13). This system provides a good frame to define resectability of pCCA, but it lacks evaluation of nodal or distant metastases.

The American Joint Committee on Cancer Staging system (AJCC/UICC) $7^{\text {th }}$ edition includes all tumor, lymph nodes, and distant metastasis (TNM) for evaluation of pCCA (table 3)(14). The AJCC/UICC staging system focuses on both local vascular invasion, lymph nodes
Table 1 - Bismuth-Corlette classification system

\begin{tabular}{ll}
\hline Type & Anatomical Location \\
\hline I & $\begin{array}{l}\text { Involving common hepatic duct distal to the biliary } \\
\text { confluence }\end{array}$ \\
\hline II & Involving the biliary confluence \\
\hline III & Involving the biliary confluence and right hepatic duct \\
\hline b & Involving the biliary confluence and left hepatic duct \\
\hline IV & Extending to the bifurcation of left and right hepatic ducts \\
\hline
\end{tabular}

invasion and distant metastases, but its use in the preoperative evaluation of resectability is minimal. Recently, the International Group of pCCA proposed a new staging system. The new system includes the Bismuth-Corlette classification, the MSKCC staging system, and the AJCC/UICC staging system. The new system includes extent of bile duct involvement, tumor size and morphology, portal vein and hepatic artery involvement, liver remnant volume and underlying liver disease, and lymph node or distant metastases (15).

\section{DIAGNOSIS}

Most patients with pCCA present with painless obstructive jaundice, which may be associated with vague abdominal pain, and weight loss. In about $10 \%$, cholangitis is the initial presentation $(6,16,17)$. On laboratory evaluation, pCCA patients show elevation of serum cholestatic parameters. Carbohydrate antigen 19-9 (CA 19-9) is the most commonly used tumor marker, however it has a poor sensitivity and specificity for early detection of pCCA (18).

Radiologically, abdominal ultrasonography has a limited role in preoperative setting. Multidetector dynamic computer tomography (CT) plays an essential role in preoperative planning. It allows evaluation of tumor extent, the extent of vascular and lymph nodes involvement $(2,5)$.

Magnetic resonance imaging (MRI) with magnetic resonance cholangio-pancreatography (MRCP) are

Table 2 - Memorial Sloan-Kettering Cancer System

\begin{tabular}{lcccc}
\hline Stage & & \multicolumn{2}{c}{ Criteria } \\
\hline & $\begin{array}{c}\text { Biliary confluence } \\
\text { invasion }\end{array}$ & $\begin{array}{c}\mathbf{2}^{\text {nd }} \text { order biliary } \\
\text { radical invasion }\end{array}$ & Portal vein invasion & Hepatic lobar atrophy \\
\hline T1 & Yes & + - unilateral & No & No \\
\hline T2 & Yes & + - unilateral & Ipsilateral & + - ipsilateral \\
\hline T3 & Yes & bilateral & Yes/No & Yes/No \\
& Yes & unilateral & contralateral & Yes/No \\
& Yes & unilateral & Yes/No & contralateral \\
& Yes & $+/-$ unilateral & bilateral & Yes/No \\
\hline
\end{tabular}


Table 3 - TNM and American Joint Committee on Cancer (AJCC)/Union for International Cancer Control (UICC) Staging Systems for Perihilar Cholangiocarcinoma

\begin{tabular}{|c|c|c|c|}
\hline Stage & \multicolumn{3}{|l|}{ Criteria } \\
\hline & \multicolumn{3}{|l|}{ Tumor $(\mathrm{T})$ stage } \\
\hline Tx & \multicolumn{3}{|c|}{ Primary tumor cannot be assessed } \\
\hline TO & \multicolumn{3}{|c|}{ No evidence of primary tumor } \\
\hline Tis & \multicolumn{3}{|c|}{ Carcinoma in situ (intraductal tumor) } \\
\hline $\mathrm{T} 1$ & \multicolumn{3}{|c|}{ Tumor confined to the bile duct, with extension up to the muscle layer or fibrous tissue } \\
\hline T2a & \multicolumn{3}{|c|}{ Tumor invades beyond the wall of the bile duct to surrounding adipose tissue } \\
\hline $\mathrm{T} 2 \mathrm{~b}$ & \multicolumn{3}{|c|}{ Tumor invades adjacent hepatic parenchyma } \\
\hline T3 & \multicolumn{3}{|c|}{ Tumor invades unilateral branches of the $\mathrm{PV}$ or $\mathrm{HA}$} \\
\hline T4 & \multicolumn{3}{|c|}{$\begin{array}{l}\text { Tumor invades main PV or its branches b/l, CHA, second-order bile ducts } \mathrm{b} / \mathrm{l} \text {, unilateral second-order bile ducts } \\
\text { with contralateral PV or HA involvement }\end{array}$} \\
\hline & \multicolumn{3}{|c|}{ Lymph Node(N) stage } \\
\hline $\mathrm{Nx}$ & \multicolumn{3}{|c|}{ Regional lymph nodes cannot be assessed } \\
\hline NO & \multicolumn{3}{|c|}{ No regional lymph node metastases } \\
\hline N1 & \multicolumn{3}{|c|}{ Regional lymph node metastasis: hilar (along CBD, cystic duct, HA or PV) } \\
\hline N2 & \multicolumn{3}{|c|}{ Metastasis to periaortic, pericaval, SMA or coeliac lymph nodes. } \\
\hline & \multicolumn{3}{|l|}{ Metastasis (M) stage } \\
\hline $\mathrm{MO}$ & \multicolumn{3}{|l|}{ No distant metastases } \\
\hline M1 & \multicolumn{3}{|l|}{ Distant metastases } \\
\hline AJCC/UICC stage & Tumor & Node & Metastasis \\
\hline 0 & Tis & NO & M0 \\
\hline 1 & $\mathrm{T} 1$ & NO & $\mathrm{MO}$ \\
\hline II & T2a or $2 b$ & NO & MO \\
\hline III A & T3 & NO & MO \\
\hline III B & T4 & NO & $\mathrm{MO}$ \\
\hline III C & Any $\mathrm{T}$ & N1 & $\mathrm{MO}$ \\
\hline IVA & Any $T$ & N2 & $\mathrm{MO}$ \\
\hline IV B & Any $\mathrm{T}$ & Any N & $\mathrm{M} 1$ \\
\hline
\end{tabular}

essential in preoperative surgical planning and evaluation of the disease extent inside the biliary tree (fig. 1)(19). A common diagnostic challenge is the distinction between benign and malignant biliary strictures. IgG4 associated cholangiopathy is a main differential diagnosis, so checking serum concentration of IgG4 is essential (20).

Positron emission tomography (PET-CT) is rarely used in the setting of pCCA $(21,22)$. Endoscopic ultrasound (EUS) can be used in the preoperative workup to detect tumor and lymph nodes extension (23). Attempts of biopsy from the pCCA or lymph nodes must be avoided as it may result in potential tumor dissemination excluding the patient from potentially curative liver transplantation $(5,22)$.

\section{PREOPERATIVE BILIARY DRAINAGE}

The role of preoperative biliary drainage (PBD) in
pCCA patients remains a controversial issue. There is no proof that routine preoperative biliary drainage facilitates resection or reduces postoperative complication (6).

PBD can be achieved percutaneously by percutaneous transhepatic biliary drainage (PTBD)(fig. 2-a), or endoscopically by endoscopic retrograde cholangiopancreatography (ERCP)(fig. 2-b,c). PTBD is more appropriate for PBD as it minimizes the risk of biliary tract seeding and inflammatory reactions (24).

The main advantages of PBD are acquisition of a diagnostic cholangiogram to evaluate the disease extent and collection of brush samples from the biliary epithelium for cytologic analysis. In contrary, the use of biliary stents had been associated with higher incidence of postoperative infectious complications $(6,24)$.

PBD can be performed selectively or totally. Selective PBD is recommended for Bismuth type III-A requiring right hemi-hepatectomy, Bismuth type IV, and 


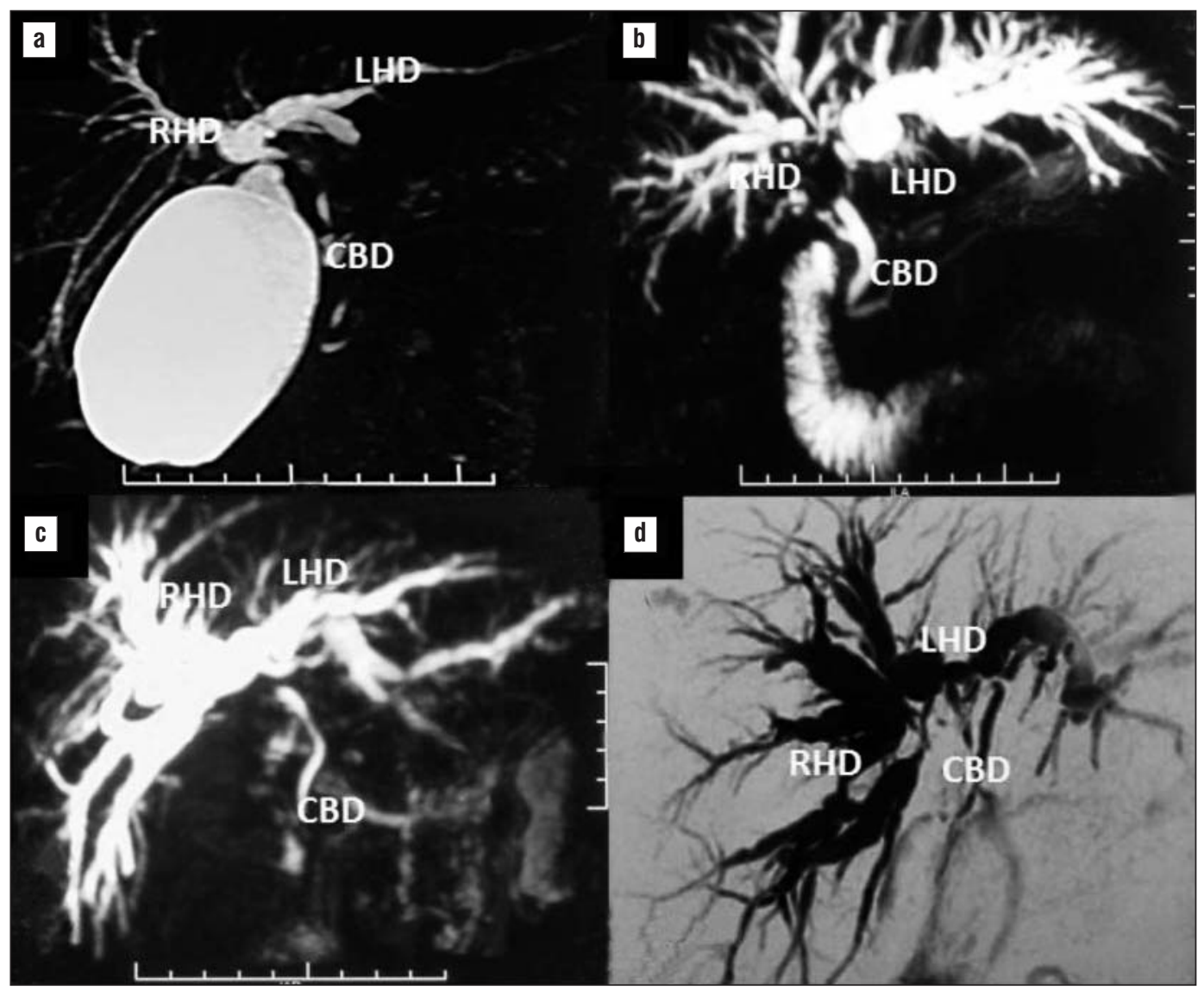

Figure 1 - Magnetic resonance cholangiopancreatography of perihilar cholangiocarcinoma.

(a) Type 1. (b) Type IIla. (c) Type IIIb.

(d) Type IV (CBD = common bile duct, RHD = right hepatic duct, LHD = left hepatic duct)

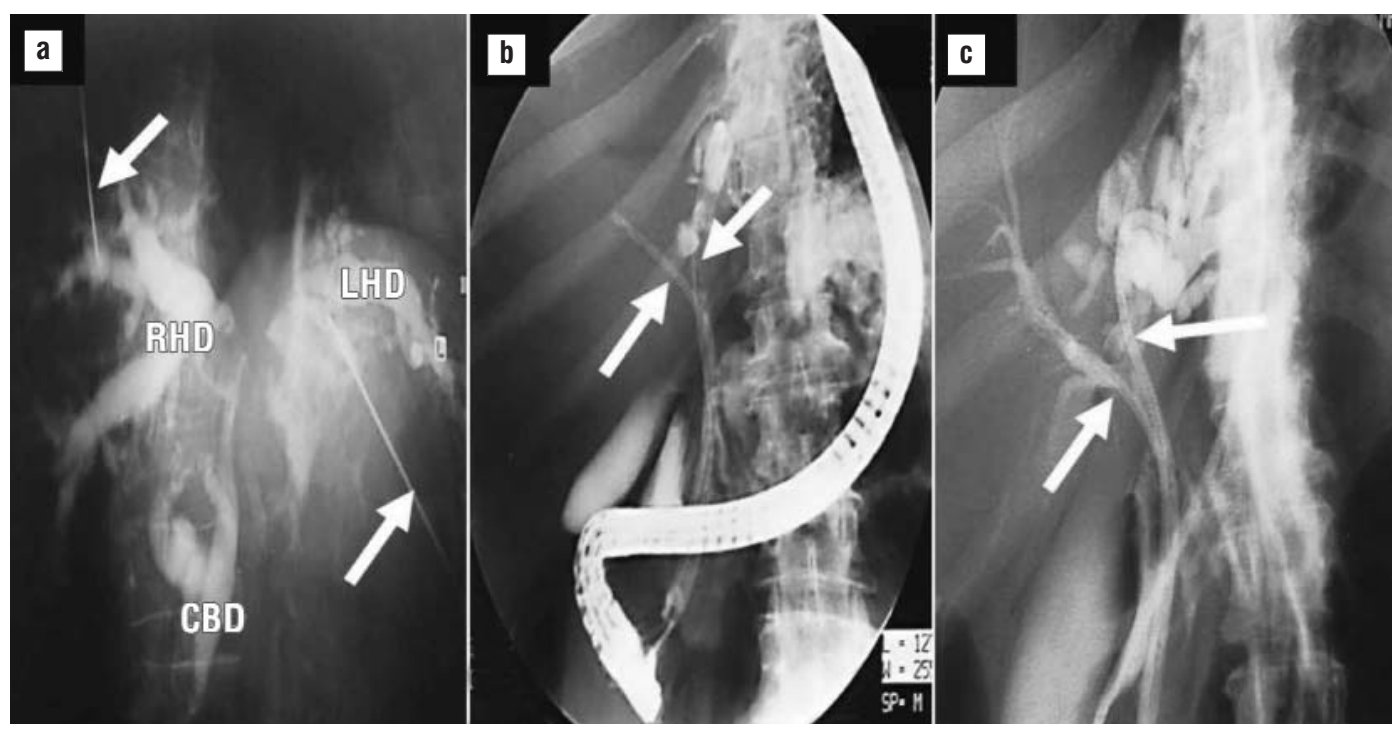

Figure 2 - (a) Percutaneous transhepatic cholangiogram for type IV lesion (arrows indicating bilateral cholangiogram needles). (b, c) Endoscopic retrograde cholangio-pancreatography for type IV lesion (arrows indicating bilateral biliary stents) (CBD = common bile duct, RHD = right hepatic duct, LHD = left hepatic duct) 
with preoperative portal vein embolization with neoadjuvant chemo-radiotherapy. This is usually sufficient in most cases. Total PBD is recommended in the development of cholangitis or slow decrease of serum bilirubin after selective $\operatorname{PBD}(24,25)$.

\section{TREATMENT}

Radical surgical resection with adequate safety margin is the standard of care for pCCA patients. In selected cases, orthotopic liver transplantation can be done.

\section{SURGICAL RESECTION}

Surgical management is the only potentially curative treatment for pCCA patients. Surgical resection combined with adjuvant or neoadjuvant therapies is the most preferred management approach.

\section{Rational of surgical treatment}

To achieve a radical resection for pCCA patients, the following criteria should be fulfilled:
* Resection of involved intra- and extrahepatic biliary tree with clear margins.

* Resection of related hemi-liver according to the tumor extension.

* Routine caudate lobectomy (segmentectomy I).

* Standard lymphadenectomy including locoregional lymph nodes.

* Biliary tract reconstruction through biliary-enteric anastomoses.

\section{Surgery from localized resection to radical resection}

Initially, isolated resection of the extrahepatic biliary system was proposed. It was associated with acceptable mortality rates, but the recurrence rate was high with rates between $50 \%$ to $70 \%$ (26).

In 1992, Bismuth et al. introduced different surgical approaches for different pCCA types depending on their anatomical classification. Isolated bile duct resection with safety margin for type I and II tumors. Hemihepatectomy with hepaticojejunostomy for types IIIa and IIIb tumors (figs. 3, 4). They

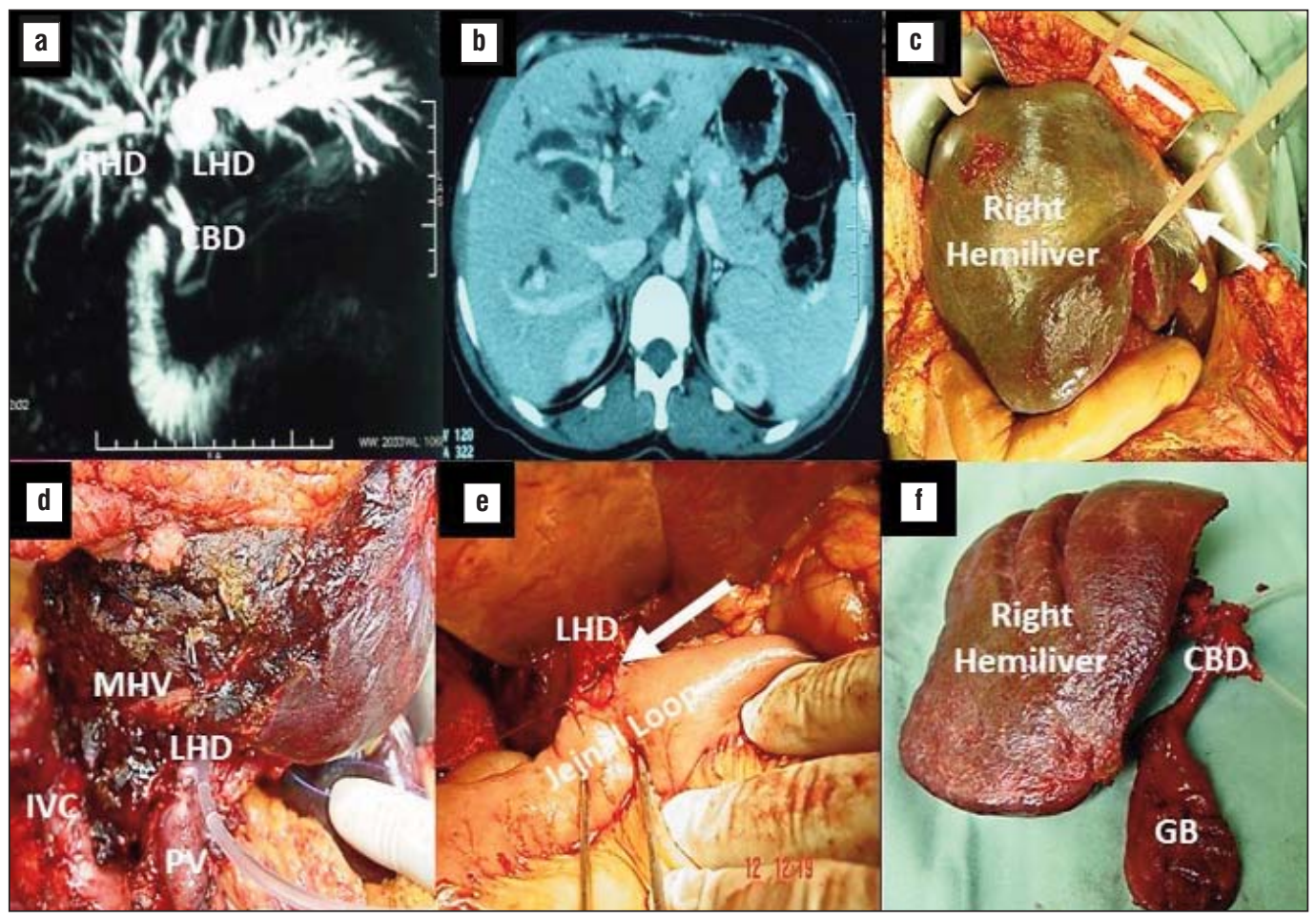

Figure 3 - Right hemi-hepatectomy for type Illa lesion. (a) Preoperative magnetic resonance cholangiopancreatography. (b) Preoperative computed tomography (portal phase). (c) Operative photo of mobilized right hemiliver with hanging maneuver (arrows indicate hanging tape). (d) Operative photo of the operative bed after right hemi-hepatectomy and caudate lobectomy and extrahepatic biliary system resection. E:Operative photo of left hepatico-jejunostomy (arrow).

(f) Postoperative specimen after right hemi-hepatectomy and caudate lobectomy and extrahepatic biliary system resection (CBD = common bile duct, $\mathrm{RHD}=$ right hepatic duct, $\mathrm{LHD}=$ left hepatic duct, $\mathrm{MHV}=$ middle hepatic vein, IVC = inferior vena cava, $\mathrm{PV}=$ portal vein, $\mathrm{GB}=$ gall bladder) 


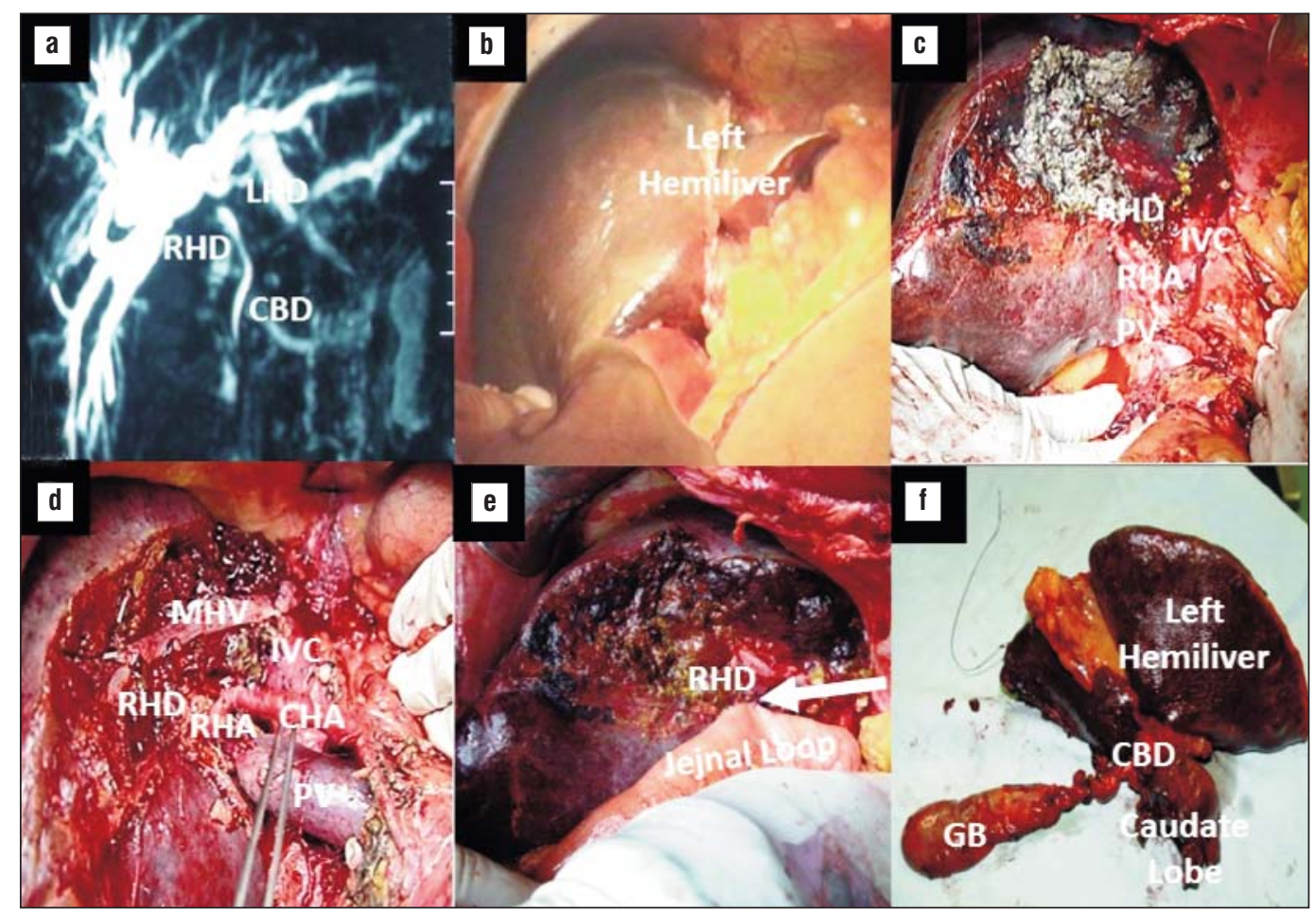

Figure 4 - Left hemi-hepatectomy for type IIlb lesion. (a) Preoperative magnetic resonance cholangiopancreatography. (b) Operative photo showing atrophic left hemi-liver. (c, d) Operative photo of the operative bed after left hemihepatectomy and caudate lobectomy and extrahepatic biliary system resection. (e) Operative photo of right hepaticojejunostomy (arrow). (f) Postoperative specimen after left hemi-hepatectomy and caudate lobectomy and extrahepatic biliary system resection $(C B D=$ common bile duct, $\mathrm{RHD}=$ right hepatic duct, $\mathrm{LHD}=$ left hepatic duct, RHA = right hepatic artery, MHV = middle hepatic vein, IVC = inferior vena cava, $\mathrm{PV}=$ portal vein, $\mathrm{CHA}=$ common hepatic artery, $\mathrm{GB}=$ gall bladder)

defined type IV tumors as unresectable (27).

In 1990, Nimura et al. introduced the principle of routine caudate segmentectomy for pCCA patients (28). Their assumption was based on the infiltrative nature of the disease which tend to spread along biliary branches of the caudate lobe that may cause tumor recurrence. Several studies have subsequently confirmed the value of this oncological principle regarding the achievement of RO resection and improved 5-year survival rates (29-31).

Nowadays, resection of the involved intra- and extrahepatic bile ducts, with related hemi-liver and caudate lobe, is the standard of care for resectable cases. With advancements of surgical techniques and perioperative care, dramatic improvement of the outcomes of those resections is noticed.

\section{Contra-indications of surgical resection}

Patients are excluded from surgical resection if they had a bilateral tumor extension involving both left and right secondary biliary radicles, unilobar involvement with encasement of contralateral portal vein or hepatic artery, bilateral vascular involvement, presence of distant metastases, underlying liver disease (advanced fibrosis, cirrhosis), if future liver remnant is less than $20-30 \%$ and no or poor response to portal vein embolization, and presence of severe co-morbidities prohibiting major surgical procedures (22).

\section{Extent of lymphadenectomy}

One of the most important prognostic factors after resection of pCCA is lymph node involvement. It had been shown that lymph node metastasis occurs in more than $30 \%$ of pCCA patients (22).

The AJCC/UICC $7^{\text {th }}$ edition recommended a minimum retrieval of 15 lymph nodes for appropriate staging (14). However, this was not accepted by most groups because of the need for extended dissection, with subsequent prolonged operation time and intraoperative blood loss. Most groups report average lymph nodes retrieval of 3-10 lymph nodes (32-34). We recommend lymphadenectomy of locoregional lymph nodes starting from 
the celiac trunk up to the hilum enbloc with the mass. The locoregional lymph nodes include the cystic duct, pericholedochal, hilar, periportal, hepatic artery, and retroduodenal nodes (35). The need for extended lymphadenectomy is no longer recommended and did not prove a survival advantage.

\section{Liver cirrhosis}

Patients with underlying liver cirrhosis are specifically complex. Cirrhotic patients are at an increased risk of bleeding, sepsis, and hepatic decompensation (36). No guideline has been issued for the management of resectable pCCA in cirrhotic patients. In the presence of cirrhosis, the management of pCCA requires careful patient selection, good perioperative care, adequate counseling on operative risk and good decision on extent of resection.

Surgical resection should be limited to patients with well compensated chronic liver diseases. The extent of surgical resection is dependent on the balance between radicality and adequate hepatic reserve in cirrhotic patients to avoid posthepatectomy liver dysfunction.

Such surgical resections should be limited to experienced surgeons in high volume centers where there is expertise in the management of liver cirrhosis and postoperative complications(35).

\section{Improvement of residual liver volume}

In pCCA cases in which resectability is prohibited by low residual liver volume (especially when extended resections are planned as right or left trisectionectomy), preoperative portal vein embolization (PVE) of the affected lobe can be done.

Makuuchi et al. firstly introduced the concept of preoperative PVE of the affected hemi-liver to induce compensatory hypertrophy of the non occluded future liver remnant and prevent posthepatectomy liver failure (37). Afterwards, Kubota et al. described the criteria to define ideal patients who will benefit from preoperative PVE, depending on indocyanine green test and hepatic volumetry (38). This concept had proved great effectiveness with acceptable morbidity and mortality rates. Abulkhir et al. in a meta-analysis regarding PVE before major hepatic resection found that the future liver volume increased by about $8-27 \%$ with morbidity rates less than $3 \%$ and no mortality. They advocated that if the liver remnant less than $20 \%$ or the degree of hypertrophy is less than $5 \%$ after preoperative PVE, hepatic resection is considered high-risk and should be contraindicated (39).
Improvement of the patients' general condition and liver functions before PVE is essential to have satisfactory outcomes. Biliary drainage is advisable before preoperative PVE to rest the liver and relief biliary radicals' dilatations in the remnant liver (4).

A newly introduced alternative for preoperative PVE in cases with low residual liver volume the ALPPS procedure. ALPPS procedure refers to Associating Liver Partition and Portal Vein Ligation for Staged Hepatectomy.

This novel approach is based on the principle that hepatic regeneration is at most stimulated by hepatic parenchymal transection together with increased portal venous blood flow. Also, it overcomes limited hepatic volume improvement due to the presence of collaterals between the residual and resected hepatic segments (40).

The procedure consists of two stages. Initially, ligation of the ipsilateral portal vein and in situ liver splitting is performed. The patient is observed for 1 to 3 weeks the assess growth of the future liver remnant. The definitive surgical resection is then performed after confirmation of adequate volume increase on CT. This procedure proved high effectiveness in cases with low residual future liver remnant in which preoperative PVE was insufficient or failed $(41,42)$.

\section{Vascular resections}

pCCA is known of its close anatomic relationship to major hepatic vasculature (portal vein and hepatic artery). So local vascular invasion is frequently faced during surgery for pCCA (4). In initial reports on pCCA, most authors did not advocate extensive vascular resections and such approaches were only limited to few case reports. Also, vascular resections were associated with increased complexity of the surgery, increased blood loss, and high perioperative mortality $(43,44)$.

With refinements of surgical techniques, several centers had reported portal vein resections for PCCA patients with acceptable perioperative morbidity and mortality (45-47). Neuhaus et al. introduced the concept of hilar-en-bloc resection or no-touch technique. This concept includes extended right hemi-hepatectomy with pre-emptive portal vein resection and reconstruction. It was associated with high post-operative mortality but with better overall survival rate (48).

With acceptance of portal venous resections, some surgeons started to address combined portal vein and hepatic artery resections and reconstructions $(49,50)$. However, this was not greatly supported by others surgeons because it is increasing the complexity of the 
operation without proven benefit on the short- or longterm outcomes (51).

Finally, we can conclude that portal vein resection is widely accepted by most centers, but the real longterm benefits from this complex surgery remain controversial. Combined hepatic artery and portal vein resection is one of the most complicated and technically demanding procedures in hepatobiliary surgery and its' benefit remains debated.

\section{Minimally invasive approach}

Laparoscopic liver resection had gained acceptance among hepatobiliary surgeons. In the field of pCCA, the application of laparoscopic approach is still not accepted as an alternative to standard open approach. Laparoscopic resection of pCCA is a technically challenging procedure including laparoscopic hepatoduodenal lymphadenectomy, hemi-hepatectomy with caudate lobectomy, and hepaticojejunostomy.

Only a limited number of case series have been reported in selected cases from highly specialized centers (52-54). Although the initial appear encouraging, the long term oncological outcomes have not been proven till now.

\section{POSTOPERATIVE ADJUVANT THERAPY}

Adjuvant chemotherapy and targeted radiation in addition to surgery is the most preferred management approach. Recent studies showed improved overall survival in pCCA patients treated with adjuvant chemoradiation (55-57). Chemotherapy decreases the risk of distant tumor recurrence while radiotherapy reduces the risk of local recurrence especially innode-positive or margin-positive (R1) patients (58).

\section{ORTHOTOPIC LIVER TRANSPLANTATION}

Orthotopic liver transplantation (OLT) with neoadjuvant chemo-radiotherapy provides a promising option in patients with unresectable tumors. OLT is preferred in patients with primary sclerosing cholangitis and/or liver cirrhosis due to the limited hepatic reserves. OLT with neoadjuvant chemoradiotherapy can achieve 5-year disease free survival rates ranging between $65-70 \%(59,60)$.

\section{Exclusion criteria from OLT}

The Mayo clinic adopted specific exclusion criteria for patients with unresectable pCCA from OLT. Those criteria include tumor size exceeding $3 \mathrm{~cm}$ in radial diameter, presence of uncontrolled infection, prior radiation or chemotherapy, prior biliary resection or attempted resection, attempted trans-peritoneal biopsy (percutaneous or EUS guided), presence of intrahepatic metastases, evidence of extrahepatic disease or lymph node spread, and history of other malignancy within the last 5 years (61).

\section{POSTOPERATIVE OUTCOMES AND SURVIVAL}

Postoperative morbidity and mortality rates have decreased in recent years. Postoperative morbidities after radical resection had been reported to range between $9-80 \%$ in previous studies as shown in table 4. Major postoperative morbidities include biliary leaks and fistulae, intraabdominal abscesses, posthepatectomy liver dysfunction, and sepsis (29). Postoperative mortality rates after radical resection range between $5-10 \%$ in previous studies and mostly related to infectious complications as shown in table 4. Posthepatectomy liver failure is an unusual cause for postoperative mortality especially in cirrhotic patients (35).

After radical resection for PCCA, the overall 5-year survival rates had been reported to be range from $11 \%$ to $45 \%$ in previous studies as shown in table 4 . Several prognostic factors had been identified to affect the survival after radical resection of pCCA. Among them, surgical margin status and lymph node metastases had been identified to be the most important prognostic factors affecting the survival $(29,46)$. Other prognostic factors include liver status, extent of liver resection, caudate lobe resection, tumor differentiation, tumoral vascular invasion, perineural tumor infiltration, and adjuvant chemotherapy and radiation $(6,35)$.

\section{NON-RESECTABLE PERIHILAR CHOLANGIOCARCINOMA}

For patients with locally unresectable tumors who are not candidates for OLT, biliary drainage together with definitive chemoradiation is the preferred approach. Definitive chemo-radiotherapy includes external beam radiotherapy plus chemotherapy (5-fluorouracil-based regimens, or gemcitabine-based regimens, or combining cisplatin with gemcitabine) with or without intraluminal brachytherapy $(16,22)$.

Biliary drainage is essential to improve patient survival and avoid complications related to recurrent cholangitis. Biliary drainage can be done endoscopically or percutaneously by self-expandable biliary stents. 
Table 4 - Studies of liver resection for perihilar cholangiocarcinoma (NA = not addressed)

\begin{tabular}{|c|c|c|c|c|c|}
\hline Author & Publication Year & Cases number & $\begin{array}{c}\text { Morbidity } \\
(\%)\end{array}$ & $\begin{array}{c}\text { Early Mortality } \\
(\%)\end{array}$ & $\begin{array}{c}5 \text { years Overall } \\
\text { Survival }(\%)\end{array}$ \\
\hline DeOliveira et al. (65) & 2007 & 173 & 62 & 5 & NA \\
\hline Hirano et al. (66) & 2010 & 94 & 45 & 4 & 36 \\
\hline Lee et al. (67) & 2010 & 302 & 43 & 3 & 36 \\
\hline Unno et al. (68) & 2010 & 125 & 49 & 8 & 35 \\
\hline Shimizu et al. (69) & 2010 & 172 & 44 & 6 & 28 \\
\hline Young et al. (70) & 2011 & 83 & 64 & 7 & 20 \\
\hline Wahab et al. (71) & 2011 & 243 & 35 & 6.6 & 16 \\
\hline Neuhaus et al. (48) & 2012 & 50 & NA & 11 & 58 \\
\hline Ribero et al. (72) & 2012 & 75 & NA & 10 & 28 \\
\hline Cannon et al. (73) & 2012 & 59 & 39 & 5.1 & NA \\
\hline De Jong et al. (46) & 2012 & 305 & $N A$ & 7 & 20 \\
\hline Matsuo et al. (74) & 2012 & 157 & 59 & 9 & 38 \\
\hline Cheng et al. (75) & 2012 & 171 & NA & 3 & 14 \\
\hline Kow et al. (76) & 2012 & 127 & 6 & 0 & 35 \\
\hline Nagino et al. (77) & 2013 & 574 & 57 & 47 & 33 \\
\hline Song et al.(78) & 2013 & 230 & 9 & 4 & 39 \\
\hline Lim et al.(79) & 2013 & 52 & 31 & 0 & 23 \\
\hline Hosokawa et al.(80) & 2014 & 61 & 51 & 3 & 25 \\
\hline Matsumoto et al.(81) & 2014 & 174 & 45 & 4 & 36 \\
\hline Xiong et al.(82) & 2015 & 52 & 34 & 4 & 13 \\
\hline
\end{tabular}

Bilateral biliary stents increase the risk of stent-related complications (62).

Novel modalities that are being used and are still under evaluation include photodynamic therapy and targeted therapies such as epidermal growth factor receptor (EGFR) tyrosine kinase inhibitors (erlotinib and laptinib), anti-EGFR antibodies (cetuximab and panitumumab), angiogenesis inhibitors (sorafenib and bevacizumab), and MEK1 and MEK2 inhibitors (selumetinib)(16, 63, 64).

In summary, pCCA is an aggressive malignancy that is increasing in the past years. Management of pCCA requires collaboration of multidisciplinary teams for tailoring of the most appropriate approach for each individual case. Currently radical resection of pCCA followed by adjuvant therapy is the standard of care. In selected patients who are not suitable for resection, neoadjuvant therapy followed by liver transplantation may offer a further approach with curative intent.

\section{Conflicts of Interest}

No conflicts of interest were declared.

\section{Grants and Financial Support}

No external funding resources.

\section{REFERENCES}

1. Lim JH. Cholangiocarcinoma: morphologic classification according to growth pattern and imaging findings. Am J Roentgenol 2003; 181(3):819-827.

2. Ghouri YA, Mian I, Blechacz B. Cancer review: Cholangiocarcinoma. J Carcinog. 2015;14:1

3. Klatskin G. Adenocarcinoma of the hepatic duct at its bifurcation within the porta hepatis. An unusual tumor with distinctive clinical and pathological features. Am J Med. 1965;38:241-56.

4. Kambakamba P, DeOliveira ML. Perihilar cholangiocarcinoma: paradigms of surgical management. Am J Surg. 2014;208(4):563-70.

5. Blechacz B. Cholangiocarcinoma: current knowledge and new developments. Gut Liver. 2017;11(1):13-26.

6. Abd EIWahab M, El Nakeeb A, El Hanafy E, Sultan AM, Elghawalby A, Askr W, et al. Predictors of long term survival after hepatic resection for hilar cholangiocarcinoma: A retrospective study of 5year survivors. World J Gastrointest Surg. 2016;8(6):436-43.

7. Endo I, Gonen M, Yopp AC, Dalal KM, Zhou Q, Klimstra D, et al. Intrahepatic cholangiocarcinoma: rising frequency, improved survival, and determinants of outcome after resection. Ann Surg. 2008; 248(1):84-96

8. Morris-Stiff G, Bhati C, Olliff S, Hübscher S, Gunson B, Mayer D, et al. Cholangiocarcinoma complicating primary sclerosing cholangitis: a 24-year experience. Dig Surg. 2008;25(2):126-32. 
9. Watanapa P, Watanapa WB. Liver fluke-associated cholangiocarcinoma. Br J Surg. 2002;89(8):962-70.

10. Lazaridis KN, Gores GJ. Cholangiocarcinoma. Gastroenterology. 2005 May;128(6):1655-67.

11. Walker NJ, Crockett PW, Nyska A, Brix AE, Jokinen MP, Sells DM, et al. Dose-additive carcinogenicity of a defined mixture of "dioxin-like compounds". Environ Health Perspect. 2005;113(1):43-8.

12. Bismuth $\mathrm{H}$, Corlette MB. Intrahepatic cholangioenteric anastomosis in carcinoma of the hilus of the liver. Surg Gynecol Obstet. 1975;140(2):170-8.

13. Jarnagin WR, Fong Y, Dellatteo RP, Gonen M, Burke EC, Bodniewicz BS J, et al. Staging, resectability, and outcome in 225 patients with hilar cholangiocarcinoma. Ann Surg. 2001;234(4):507-17; discussion 517-9.

14. Edge S, Byrd DR, Compton CC, Fritz AG, Greene FL, Trotti A, editors. AJCC Cancer Staging Manual, 7th ed. Springer; 2010.

15. Deoliveira ML, Schulick RD, Nimura Y, Rosen C, Gores G, Neuhaus $P$, et al. New staging system and a registry for perihilar cholangiocarcinoma. Hepatology. 2011;53(4):1363-71.

16. Razumilava N, Gores GJ. Classification, diagnosis, and management of cholangiocarcinoma. Clin Gastroenterol Hepatol. 2013;11(1):1321.e1; quiz e3-4. Epub 2012 Sep 13

17. Brandi G, Venturi M, Pantaleo MA, Ercolani G; GICO Collaborators (8) Cholangiocarcinoma: Current opinion on clinical practice diagnostic and therapeutic algorithms: A review of the literature and a long-standing experience of a referral center. Dig Liver Dis. 2016;48(3):231-41. Epub 2015 Nov 28.

18. Charatcharoenwitthaya P, Enders FB, Halling KC, Lindor KD. Utility of serum tumor markers, imaging, and biliary cytology for detecting cholangiocarcinoma in primary sclerosing cholangitis. Hepatology. 2008;48(4):1106-17.

19. Masselli G, Manfredi R, Vecchioli A, Gualdi G. MR imaging and MR cholangiopancreatography in the preoperative evaluation of hilar cholangiocarcinoma: correlation with surgical and pathologic findings. Eur Radiol. 2008;18(10):2213-21.

20. Zen Y, Kawakami H, Kim JH. IgG4-related sclerosing cholangitis: all we need to know. J Gastroenterol. 2016;51(4):295-312.

21. Moon CM, Bang S, Chung JB, Park SW, Song SY, Yun M, et al. Usefulness of $18 \mathrm{~F}$ fluorodeoxyglucose positron emission tomography in differential diagnosis and staging of cholangiocarcinomas. J Gastroenterol Hepatol. 2008;23(5):759-65. Epub 2007 Oct 10.

22. Mansour JC, Aloia TA, Crane CH, Heimbach JK, Nagino M, Vauthey JN. Hilar cholangiocarcinoma: expert consensus statement. HPB (Oxford). 2015;17(8):691-9

23. Gleeson FC, Rajan E, Levy MJ, Clain JE, Topazian MD, Harewood GC, et al. EUS-guided FNA of regional lymph nodes in patients with unresectable hilar cholangiocarcinoma. Gastrointest Endosc. 2008; 67(3):438-43. Epub 2007 Dec 3.

24. Paik WH, Loganathan N, Hwang JH. Preoperative biliary drainage in hilar cholangiocarcinoma: when and how? World J Gastrointest Endosc. 2014:6(3):68-73

25. Celotti A, Solaini L, Montori G, Coccolini F, Tognali D, Baiocchi G. Preoperative biliary drainage in hilar cholangiocarcinoma: systematic review and meta-analysis. Eur J Surg Oncol. 2017;43(9):1628-1635.

26. Evander A, Fredlund P, Hoevels J, Ihse I, Bengmark S. Evaluation of aggressive surgery for carcinoma of the extrahepatic bile ducts. Ann Surg. 1980;191(1):23-9.

27. Bismuth $\mathrm{H}$, Nakache $\mathrm{R}$, Diamond $\mathrm{T}$. Management strategies in resection for hilar cholangiocarcinoma. Ann Surg. 1992;215(1):31-8.

28. Nimura Y, Hayakawa N, Kamiya J, Kondo S, Shionoya S. Hepatic segmentectomy with caudate lobe resection for bile duct carcinoma of the hepatic hilus. World J Surg. 1990;14(4):535-43; discussion 544.

29. Wahab MA, Sultan AM, Salah T, Fathy O, Elebidy G, Elshobary M, et al. Caudate lobe resection with major hepatectomy for central cholangiocarcinoma: is it of value? Hepatogastroenterology. 2012; 59(114):321-4

30. Dinant S, Gerhards MF, Busch OR, Obertop H, Gouma DJ, Van Gulik TM. The importance of complete excision of the caudate lobe in resection of hilar cholangiocarcinoma. HPB (Oxford). 2005; 7(4):263-7.
31. Endo I, Matsuyama R, Taniguchi K, Sugita M, Takeda K, Tanaka K, et al. Right hepatectomy with resection of caudate lobe and extrahepatic bile duct for hilar cholangiocarcinoma. J Hepatobiliary Pancreat Sci. 2012;19(3):216-24.

32. Aoba T, Ebata T, Yokoyama Y, Igami T, Sugawara G, Takahashi Y, et al. Assessment of nodal status for perihilar cholangiocarcinoma: location, number, or ratio of involved nodes. Ann Surg. 2013; 257(4):718-25.

33. Ito K, Ito H, Allen PJ, Gonen M, Klimstra D, D'Angelica MI, et al. Adequate lymph node assessment for extrahepatic bile duct adenocarcinoma. Ann Surg. 2010 ;251(4):675-81.

34. Guglielmi A, Ruzzenente A, Campagnaro T, Pachera S, Conci S, Valdegamberi $A$, et al. Prognostic significance of lymph node ratio after resection of peri-hilar cholangiocarcinoma. HPB (Oxford). 2011:13(4):240-5.

35. Abdelwahab M, El Nakeeb A, Salah T, Hamed H, Ali M, El Sorogy M, et al. Hilar cholangiocarcinoma in cirrhotic liver: A case-control study. Int J Surg. 2014;12(8):762-7.

36. Farnsworth N, Fagan, Berger DH, Awad SS. Child Turcotte-Pugh versus MELD score as a predictor of outcome after elective and emergent surgery in cirrhotic patients. Am J Surg. 2004;188(5):580-3.

37. Makuuchi M, Thai BL, Takayasu K, Takayama T, Kosuge T, Gunvén P, et al. Preoperative portal embolization to increase safety of major hepatectomy for hilar bile duct carcinoma: a preliminary report. Surgery. 1990;107(5):521-7.

38. Kubota K, Makuuchi M, Kusaka K, Kobayashi T, Miki K, Hasegawa K, et al. Measurement of liver volume and hepatic functional reserve as a guide to decision-making in resectional surgery for hepatic tumors. Hepatology. 1997;26(5):1176-81.

39. Abulkhir A, Limongelli P, Healey AJ, Damrah O, Tait P, Jackson J, et al. Preoperative portal vein embolization for major liver resection: a meta-analysis. Ann Surg. 2008;247(1):49-57.

40. Schnitzbauer AA, Lang SA, Goessmann H, Nadalin S, Baumgart J, Farkas SA, et al. Right portal vein ligation combined with in situ splitting induces rapid left lateral liver lobe hypertrophy enabling 2staged extended right hepatic resection in small-for-size settings. Ann Surg. 2012;255(3):405-14.

41. de Santibañes E, Alvarez FA, Ardiles V. How to avoid postoperative liver failure: a novel method. World J Surg. 2012;36(1):125-8.

42. Capussotti L, Muratore A, Baracchi F, Lelong B, Ferrero A, Regge D, et al. Portal vein ligation as an efficient method of increasing the future liver remnant volume in the surgical treatment of colorectal metastases. Arch Surg. 2008; 143(10):978-82; discussion 982.

43. Launois B, Campion JP, Brissot P, Gosselin M. Carcinoma of the hepatic hilus. Surgical management and the case for resection. Ann Surg. 1979;190(2):151-7.

44. Beazley RM, Hadjis N, Benjamin IS, Blumgart LH. Clinicopathological aspects of high bile duct cancer. Experience with resection and bypass surgical treatments. Ann Surg. 1984;199(6):623-36.

45. Ebata T, Nagino M, Kamiya J, Uesaka K, Nagasaka T, Nimura Y. Hepatectomy with portal vein resection for hilar cholangiocarcinoma: audit of 52 consecutive cases. Ann Surg. 2003:238(5):720-7.

46. de Jong MC, Marques H, Clary BM, Bauer TW, Marsh JW, Ribero D, et al. The impact of portal vein resection on outcomes for hilar cholangiocarcinoma: a multi institutional analysis of 305 cases. Cancer. 2012;118(19):4737-47.

47. Nimura Y, Kamiya J, Kondo S, Nagino M, Uesaka K, Oda K, et al. Aggressive preoperative management and extended surgery for hilar cholangiocarcinoma: Nagoya experience. J Hepatobiliary Pancreat Surg. 2000;7(2):155-62.

48. Neuhaus $P$, Thelen A, Jonas S, Puhl G, Denecke T, Veltzke-Schlieker $W$, et al. Oncological superiority of hilar en bloc resection for the treatment of hilar cholangiocarcinoma. Ann Surg Oncol. 2012;19(5): 1602-8. Epub 2011 Oct 1.

49. Nagino M, Nimura Y, Nishio H, Ebata T, Igami T, Matsushita M, et al. Hepatectomy with simultaneous resection of the portal vein and hepatic artery for advanced perihilar cholangiocarcinoma: an audit of 50 consecutive cases. Ann Surg. 2010:252(1):115-23.

50. Ebata T, Ito T, Yokoyama Y, Igami T, Sugawara G, Mizuno T, et al. Surgical technique of hepatectomy combined with simultaneous resection of hepatic artery and portal vein for perihilar cholangio- 
carcinoma. J Hepatobiliary Pancreat Sci. 2014;21(8):E57-61.

51. Miyazaki M, Kato A, Ito H, Kimura F, Shimizu H, Ohtsuka M, et al. Combined vascular resection in operative resection for hilar cholangiocarcinoma: does it work or not? Surgery. 2007;141(5):581-8.

52. Gumbs AA, Jarufe N, Gayet B. Minimally invasive approaches to extrapancreatic cholangiocarcinoma. Surg Endosc. 2013;27(2):40614. Epub 2012 Aug 28.

53. Lee W, Han HS, Yoon YS, Cho JY, Choi Y, Shin HK, et al. Laparoscopic resection of hilar cholangiocarcinoma. Ann Surg Treat Res. 2015;89(4):228-32.

54. Cho A, Yamamoto H, Kainuma O, Muto Y, Yanagibashi H, Tonooka T, et al. Laparoscopy in the management of hilar cholangiocarcinoma. World J Gastroenterol. 2014;20(41):15153-7.

55. Cheng Q, Luo X, Zhang B, Jiang X, Yi B, Wu M. Predictive factors for prognosis of hilar cholangiocarcinoma: postresection radiotherapy improves survival. Eur J Surg Oncol. 2007;33(2):202-7. Epub 2006 Nov 7.

56. Kim TH, Han SS, Park SJ, Lee WJ, Woo SM, Moon SH, et al. Role of adjuvant chemoradiotherapy for resected extrahepatic biliary tract cancer. Int J Radiat Oncol Biol Phys. 2011 Dec 1;81(5):e853-9.

57. Todoroki T, Ohara K, Kawamoto T, Koike N, Yoshida S, Kashiwagi H, et al. Benefits of adjuvant radiotherapy after radical resection of locally advanced main hepatic duct carcinoma. Int J Radiat Oncol Biol Phys. 2000:46(3):581-7.

58. Borghero Y, Crane CH, Szklaruk J, Oyarzo M, Curley S, Pisters PW, et al. Extrahepatic bile duct adenocarcinoma: patients at high risk for local recurrence treated with surgery and adjuvant chemoradiation have an equivalent overall survival to patients with standard-risk treated with surgery alone. Ann Surg Oncol. 2008;15(11):3147-56.

59. Darwish Murad S, Kim WR, Harnois DM, Douglas DD, Burton J, Kulik LM, et al. Efficacy of neoadjuvant chemoradiation, followed by liver transplantation, for perihilar cholangiocarcinoma at 12 US centers. Gastroenterology. 2012;143(1):88-98.e3; quiz e14.

60. Rea DJ, Heimbach JK, Rosen CB, Haddock MG, Alberts SR, Kremers WK, et al. Liver transplantation with neoadjuvant chemoradiation is more effective than resection for hilar cholangiocarcinoma. Ann Surg. 2005;242(3):451-8; discussion 458-61.

61. Rosen CB, Heimbach JK, Gores GJ. Liver transplantation for cholangiocarcinoma. Transpl Int. 2010;23(7):692-7.

62. van der Gaag NA, Rauws EA, van Eijck CH, Bruno MJ, van der Harst $\mathrm{E}$, Kubben FJ, et al. Preoperative biliary drainage for cancer of the head of the pancreas. N Engl J Med. 2010;362(2):129-37.

63. Andersen JB, Spee B, Blechacz BR, Avital I, Komuta M, Barbour A, et al. Genomic and genetic characterization of cholangiocarcinoma identifies therapeutic targets for tyrosine kinase inhibitors. Gastroenterology. 2012;142(4):1021-1031.e15

64. Lee J, Park SH, Chang HM, Kim JS, Choi HJ, Lee MA, et al. Gemcitabine and oxaliplatin with or without erlotinib in advanced biliary-tract cancer: A multicentre, open-label, randomised, phase 3 study. Lancet Oncol. 2012;13(2):181-8. Epub 2011 Dec 20.

65. DeOliveira ML, Cunningham SC, Cameron JL, Kamangar F, Winter $\mathrm{JM}$, Lillemoe KD, et al. Cholangiocarcinoma: thirty-one-year experience with 564 patients at a single institution. Ann Surg. 2007; 245(5):755-62.

66. Hirano S, Kondo S, Tanaka E, Shichinohe T, Tsuchikawa T, Kato K, et al. Outcome of surgical treatment of hilar cholangiocarcinoma: a special reference to postoperative morbidity and mortality. J Hepatobiliary Pancreat Sci. 2010;17(4):455-62. Epub 2009 Oct 8

67. Lee SG, Song GW, Hwang S, Ha TY, Moon DB, Jung DH, et al.
Surgical treatment of hilar cholangiocarcinoma in the new era: the Asan experience. J Hepatobiliary Pancreat Sci. 2010;17(4):476-89. Epub 2009 Oct 23.

68. Unno M, Katayose Y, Rikiyama T, Yoshida H, Yamamoto K, Morikawa $\mathrm{T}$, et al. Major hepatectomy for perihilar cholangiocarcinoma. J Hepatobiliary Pancreat Sci. 2010;17(4):463-9. Epub 2009 Nov 26.

69. Shimizu H, Kimura F, Yoshidome H, Ohtsuka M, Kato A, Yoshitomi $\mathrm{H}$, et al. Aggressive surgical resection for hilar cholangiocarcinoma of the left-side predominance: radicality and safety of left-sided hepatectomy. Ann Surg. 2010; 251(2):281-6.

70. Young AL, Prasad KR, Toogood GJ, Lodge JP. Surgical treatment of hilar cholangiocarcinoma in a new era: comparison among leading Eastern and Western centers, Leeds. J Hepatobiliary Pancreat Sci. 2010;17(4):497-504. Epub 2009 Oct 28.

71. Abdel Wahab M, Fathy O, Sultan AM, Salah T, Elshoubary M, Abo Elyazid AY, et al. Hilar cholangiocarcinoma fifteen-year experience with 243 patients at a single Egyptian center J Solid Tumors. 2011;1(3):112-9.

72. Ribero D, Amisano M, Lo Tesoriere R, Rosso S, Ferrero A, Capussotti L. Additional resection of an intraoperative marginpositive proximal bile duct improves survival in patients with hilar cholangiocarcinoma. Ann Surg. 2011;254(5):776-81; discussion 781-3.

73. Cannon RM, Brock G, Buell JF. Surgical resection for hilar cholangiocarcinoma: experience improves resectability. HPB (Oxford). 2012;14(2):142-9. Epub 2011 Dec 12.

74. Matsuo K, Rocha FG, Ito K, D'Angelica MI, Allen PJ, Fong Y, et al. The Blumgart preoperative staging system for hilar cholangiocarcinoma: analysis of resectability and outcomes in 380 patients. J Am Coll Surg. 2012;215(3):343-55.

75. Cheng QB, Yi B, Wang JH, Jiang XQ, Luo XJ, Liu C, et al. Resection with total caudate lobectomy confers survival benefit in hilar cholangiocarcinoma of Bismuth type III and IV. Eur J Surg Oncol. 2012;38(12):1197-203.

76. Kow AW, Wook CD, Song SC, Kim WS, Kim MJ, Park HJ, et al. Role of caudate lobectomy in type III A and III B hilar cholangiocarcinoma: a 15-year experience in a tertiary institution. World $\mathrm{J}$ Surg. 2012;36(5):1112-21.

77. Nagino M, Ebata T, Yokoyama Y, Igami T, Sugawara G, Takahashi Y, et al. Evolution of surgical treatment for perihilar cholangiocarcinoma: a single-center 34-year review of 574 consecutive resections. Ann Surg. 2013;258(1):129-40.

78. Song SC, Choi DW, Kow AW, Choi SH, Heo JS, Kim WS, et al. Surgical outcomes of 230 resected hilar cholangiocarcinoma in a single centre. ANZ J Surg. 2013;83(4):268-74. Epub 2012 Sep 3.

79. Lim JH, Choi GH, Choi SH, Kim KS, Choi JS, Lee WJ. Liver resection for Bismuth type I and Type II hilar cholangiocarcinoma. World J Surg. 2013:37(4):829-37. doi: 10.1007/s00268-013-1909-9.

80. Hosokawa I, Shimizu H, Yoshidome H, Ohtsuka M, Kato A, Yoshitomi $\mathrm{H}$, et al. Surgical strategy for hilar cholangiocarcinoma of the left-side predominance: current role of left trisectionectomy. Ann Surg. 2014:259(6):1178-85.

81. Matsumoto N, Ebata T, Yokoyama Y, Igami T, Sugawara G, Shimoyama $Y$, et al. Role of anatomical right hepatic trisectio nectomy for perihilar cholangiocarcinoma. Br J Surg. 2014; 101(3):261-8.

82. Xiong J, Nunes QM, Huang W, Wei A, Ke N, Mai G, et al. Major hepatectomy in Bismuth types I and II hilar cholangiocarcinoma. J Surg Res. 2015;194(1):194-201. Epub 2014 Oct 22. 